\title{
O perfil dos diretores das escolas públicas no Brasil
}

\author{
The Brazilian school principals' profile \\ El perfil sociodemográfico de los directores de las \\ escuelas brasileñas
}

\author{
Ana Cristina Prado de Oliveira \\ Universidade Federal do Estado do Rio de Janeiro (Unirio), Rio de Janeiro/RJ - Brasil \\ Emília Giordano \\ Fundação de Apoio às Escolas Técnicas (Faetec), Rio de Janeiro/RJ - Brasil
}

\begin{abstract}
Resumo
Este artigo apresenta uma análise do perfil sociodemográfico de diretores das escolas públicas brasileiras, a partir dos dados da Prova Brasil (2007 a 2015). Dando especial destaque aos aspectos relacionados à sua formação inicial e ao seu acesso ao cargo, ressaltamos a diversidade encontrada nos dados coletados entre os estados brasileiros, assim como analisamos possíveis associações entre esses dados e a agenda política educacional sobre o tema. Considerando a centralidade da gestão escolar para a qualidade do trabalho desenvolvido na escola (ALVES; FRANCO, 2008; LEITHWOOD, 2009), acreditamos que a reflexão proposta auxiliará no debate sobre possíveis aspectos da gestão escolar relacionados ao desempenho educacional.
\end{abstract}

Palavras-chave: Gestão escolar, Diretores escolares, Políticas educacionais

\begin{abstract}
This paper presents an analysis of the sociodemographic profile of Brazilian public school principals based on data from "Prova Brasil" (2007 to 2015). With special emphasis on the aspects related to their initial academic level and their access to this position, we highlight the diversity found in the collected data among Brazilian states and analyze possible associations between these data and the educational policy agenda on the topic. Considering the centrality of school management to the quality of the work developed in the school (ALVES; FRANCO, 2008; LEITHWOOD, 2009), we believe that the proposed reflection will help the debate about possible aspects of the school management related to educational performance.
\end{abstract}

Keywords: School management, School principals, Educational policies.

\section{Resumen}

Este artículo presenta un análisis del perfil sociodemográfico de los directores de las escuelas públicas brasileñas, basado en los datos de la "Prova Brasil" (2007 a 2015). Con especial énfasis en los aspectos relacionados a su formación inicial y a su acceso al cargo, resaltamos la diversidad encontrada en los datos entre los estados brasileños así como, analizamos posibles asociaciones entre esos datos y la agenda política educativa sobre el tema. Considerando que los directores escolares producen un cambio en la calidad del trabajo desarrollado en la escuela (ALVES y FRANCO, 2008, LEITHWOOD, 2009, etc.) creemos que la reflexión propuesta ayudará en el debate sobre posibles aspectos de la gestión escolar relacionados al desempeño educativo.

Palabras clave: Gestión escolar, Directores escolares, Políticas educativas

Revista Educação Online, Rio de Janeiro, n. 27, jan-abr 2018, p. 49-72 


\section{Introdução}

O presente artigo propõe uma análise do perfil sociodemográfico de diretores e diretoras das escolas públicas brasileiras, a partir dos dados dos questionários contextuais aplicados junto a cada edição da Prova Brasil (2007 a 2015). Na análise, daremos especial destaque aos aspectos relacionados à formação inicial e ao acesso ao cargo, dados fundamentais para a discussão de políticas públicas que considerem a centralidade do papel dos diretores e diretoras, à frente das escolas públicas brasileiras, para a qualidade do trabalho desenvolvido na escola (ALVES; FRANCO, 2008; LEITHWOOD; SUN, 2009). Analisamos também possíveis associações entre esses dados (distribuídos regionalmente) e a agenda política educacional sobre o tema, considerando a descentralização federativa nas iniciativas que envolvem as atribuições do cargo.

Nos últimos anos, pesquisas sobre a eficácia escolar têm demonstrado a relevância de características escolares para a minimização dos efeitos de origem social na trajetória escolar (SAMMONS, 2008; ALVES; FRANCO, 2008). Dentre esses fatores, destacamos a centralidade da gestão escolar para a qualidade do trabalho desenvolvido na escola, conforme apontam Leithwood (2009), Soares (2007), entre outros. Estudos realizados em nosso grupo de pesquisa demonstraram a associação significativa e positiva entre o Índice de Liderança do Diretor (percebido pelos professores) e a proficiência média dos alunos em matemática (OLIVEIRA; WALDHELM, 2016; OLIVEIRA; CARVALHO, 2015; OLVEIRA, 2015). Assim, compreendendo o trabalho dos diretores e diretoras como fundamental para o cumprimento dos objetivos escolares, como será discutido mais adiante, consideramos essencial conhecer e analisar as características do perfil dos diretores e diretoras das escolas públicas brasileiras.

Os dados utilizados neste trabalho foram extraídos das bases de dados do Sistema de Avaliação da Educação Básica - Saeb, disponibilizados pelo Instituto Nacional de Estudos e Pesquisas Educacionais Anísio Teixeira - Inep. Os questionários socioeconômicos que acompanham cada edição da aplicação da Prova Brasil são direcionados aos diretores das escolas, aos professores e alunos das séries avaliadas e aos aplicadores do teste. Na página do Inep, encontramos a justificativa e o universo abrangido pelos questionários: 
Os Questionários da Prova Brasil servem como instrumentos de coleta de informações sobre aspectos da vida escolar, do nível socioeconômico, capital social e cultural de estudantes. Docentes de português e matemática das séries avaliadas e gestores das escolas, também são convidados a responder questionários que possibilitam conhecer a formação profissional, práticas pedagógicas, nível socioeconômico e cultural, estilos de liderança e formas de gestão. Os questionários destinados às professoras e professores, assim como diretoras e diretores, são entregues pelos aplicadores antes da realização do teste e devem ser recolhidos ao final da prova. ${ }^{1}$

Para este estudo, foram utilizadas as respostas dos diretores aos questionários contextuais das edições de 2007 a 2015 da Prova Brasil. Vale ressaltar que o levantamento desses dados é considerado praticamente censitário para o universo das escolas públicas brasileiras, uma vez que a Prova Brasil é aplicada em todas as escolas públicas com mais de 20 alunos matriculados na série avaliada. O quadro abaixo apresenta a distribuição dos dados considerados neste estudo:

\section{Quadro 1: Dados utilizados no estudo}

\begin{tabular}{|l|r|r|r|r|r|}
\hline & \multicolumn{1}{|c|}{2007} & \multicolumn{1}{|c|}{$2009^{2}$} & \multicolumn{1}{c|}{2011} & \multicolumn{1}{c|}{2013} & \multicolumn{1}{c|}{2015} \\
\hline Total de questionários (N) & 47.596 & 49.323 & 56.222 & 52.829 & \multicolumn{1}{|c|}{52.341} \\
\hline Total ou parcialmente preenchidos & $99,75 \%$ & $100 \%$ & $98,2 \%$ & $100 \%$ & $100 \%$ \\
\hline Não preenchido & $0,25 \%$ & $0 \%$ & $1,8 \%$ & $0 \%$ & $0 \%$ \\
\hline
\end{tabular}

Fonte: Produzido pelas autoras, com dados do Inep

A organização e análise dos dados apresentados neste trabalho propõem ampliar o debate sobre possíveis aspectos da gestão escolar relacionados ao desempenho educacional, especialmente, destacar as diferenças desses aspectos entre os estados brasileiros, considerando a diversidade políticoadministrativa nesse campo.

$\mathrm{O}$ artigo se organiza em seis seções, incluindo essa Introdução. $\mathrm{Na}$ segunda seção, trazemos a fundamentação teórica sobre a gestão escolar e a centralidade da função; na terceira, apresentamos os(as) diretores(as) das escolas públicas brasileiras: perfil do período de 2007 a 2015, considerando os dados sociodemográficos e aqueles referentes à sua formação e experiência profissional; a quarta seção aborda a questão do acesso ao cargo de diretor(a) escolar como consequência das diferentes políticas no território nacional, mostrando as principais diferenças nesse aspecto entre as unidades da

\footnotetext{
1 Informação disponível no site do Inep: <http://provabrasil.inep.gov.br/questionariossocioeconomicos>. Acesso em: 18 de nov. 2012.

2 Para esta edição, consideramos apenas os questionários parcialmente ou totalmente preenchidos, uma vez que houve um número expressivo de questionários em branco $(15,5 \%)$
}

Revista Educação Online, Rio de Janeiro, n. 27, jan-abr 2018, p. 49-72 
federação; na quinta seção, falamos sobre a formação inicial e continuada dos(as) diretores(as) das escolas públicas brasileiras, procurando aprofundar o contraste dessas informações nos diversos estados brasileiros; finalmente, na última seção, tecemos as nossas considerações finais, com algumas conclusões que julgamos relevantes na análise realizada.

\section{0 diretor e a gestão escolar}

O título de diretor remete, a princípio, às definições de chefia, comando, administração, àquele que está à frente de uma instituição. E quais seriam as possíveis definições e representações que o cargo ou função de diretor(a) poderia assumir, ao definirmos a escola enquanto seu espaço de atuação? Especialmente para os fins deste estudo, tornou-se fundamental compreender a função do(a) diretor(a) escolar em suas diversas nuances, para além da gestão ou administração de sua unidade. Em se tratando do ambiente escolar, o(a) diretor(a) assume diferentes demandas e tarefas: administrativas, burocráticas, relacionais, pedagógicas, entre outras. Entendendo que elas não são excludentes ou antagônicas, como argumentaram Paro (2015) e Souza (2006), discutiremos o papel do(a) diretor(a) da escola pública, iniciando pela definição de seu cargo enquanto funcionário(a) público(a), destacando a centralidade política da direção escolar.

Souza (2012, p.160) considera que não se pode isolar a ação administrativa do poder que está contido nela. Nesse sentido, é preciso considerar sua natureza política e representativa, a partir da legislação e das atribuições desse cargo. Nesse sentido, podemos considerar que todas as relações estabelecidas entre o(a) diretor(a) e os(as) professores(as) são pautadas por essa dinâmica de poder, na qual o(a) diretor(a) estabelece suas estratégias para conduzir a escola. Concordamos com Pereira (1967), no sentido de que a referência de autoridade está no cargo da direção escolar, e não em determinado diretor(a) em si. Contudo, consideramos que as formas de exercer essa autoridade são as mais variadas e refletem a trajetória pessoal do(a) diretor(a), sua formação acadêmica e sua experiência no exercício do cargo ou em outros setores educacionais. As estratégias adotadas na condução da escola envolvem negociações, diálogos e decisões. Acreditamos que o nível de 
participação e abertura estabelecido nessa relação definirá diferentes estilos de liderança do(a) diretor(a) na escola.

$\mathrm{O}$ (a) diretor(a) escolar da rede pública de ensino no Brasil é um(a) funcionário(a) público(a), vinculado à União, estado ou município, dependendo do pertencimento de sua unidade escolar. Há uma questão de definição legal em relação à compreensão da natureza do vínculo do(a) diretor(a) escolar: enquanto cargo comissionado, o(a) diretor(a) escolar se enquadra como "servidor de carreira"3. Os planos de remuneração e as políticas de admissão ficam a cargo dos respectivos poderes ${ }^{4}$. Assim, estando legalmente investido em uma função pública, o(a) diretor(a) escolar cumpre um papel administrativo, que o vincula tanto ao poder que o nomeou quanto à instituição que dirige e representa. Sobre o seu papel enquanto funcionário(a) público(a), Souza (2006, p.171) considera que "Como servidor público, o diretor é um burocrata, no sentido weberiano do termo. E é sua função, dentre outras questões, fazer a interlocução entre o Estado e a comunidade escolar e, como tal, exerce um papel de liderança local". A burocracia, conforme visualizada e descrita por Weber (1977) é um tipo ideal de organização que, provavelmente, não encontra réplica na realidade, mas funciona como importante modelo de análise sociológica e política. A burocracia weberiana nos remete à natureza de dever do funcionário que ocupa um cargo.

Enquanto funcionário público, burocrata, o(a) diretor(a) ocupa sua posição investido(a) pelo poder que o(a) nomeou, o que significa que um dos papéis que desempenha é o de representante do Estado. Entretanto, ele(a) é, também, representante dos(as) profissionais da escola e da comunidade na instituição escolar. Essa múltipla representação remete ao caráter político que confere centralidade à direção escolar. No caso da escolha dos diretores(as) para as escolas públicas brasileiras, há uma descentralização na definição do acesso à função. A Constituição Federal de 1988 e a Lei de Diretrizes e Bases da Educação Nacional - LDBN 9394/96, apesar de defenderem o princípio da gestão democrática nas escolas, não o estendem para a escolha do(a) diretor(a) escolar. De fato, a legislação deixa a cargo de cada ente federado as definições referentes à carreira de diretor(a) escolar, inclusive as formas de acesso à

\footnotetext{
${ }^{3}$ De acordo com os Incisos II e V do Artigo 37 de nossa Constituição Federal (BRASIL, 1988).

4 "(Art. 39) A União, os Estados, o Distrito Federal e os Municípios instituirão conselho de política de administração e remuneração de pessoal, integrado por servidores designados pelos respectivos Poderes" (BRASIL, 1998).
}

Revista Educação Online, Rio de Janeiro, n. 27, jan-abr 2018, p. 49-72 
função. Como resultado, temos discrepâncias entre os resultados das unidades federativas nesse aspecto, como será apresentado.

Assim, retomamos a complexa questão da representatividade no exercício do cargo de diretor(a) escolar: ele(a) é um(a) representante legítimo do Estado, por ele empoderado e a ele devedor, no sentido weberiano do termo, de seu cargo e lealdade. E é, ao mesmo tempo, representante dos seus pares, professores(as), já que, na grande maioria dos casos, exerce essa profissão antes de assumir a direção escolar e tem a licenciatura como formação inicial, primordialmente (como mostram os dados deste trabalho). Considera-se, ainda, a sua representatividade junto à comunidade na qual a escola se insere, especialmente, quando ela pode ser legitimada através da escolha do(a) diretor(a) em processos de consulta pública, proporcionando um maior sentimento de pertencimento de toda comunidade e possibilitando respectivas responsabilizações.

Essa tensão identitária, cujo cerne procuramos descrever, tornou-se central na nossa reflexão, ao longo do trabalho no estudo do perfil do(a) diretor(a) da escola pública brasileira.

Conhecer e analisar as características dos(as) diretores(as) das escolas públicas brasileiras, é o objetivo deste trabalho. Alguns estudos se dedicaram a essa tarefa nos últimos anos, entre eles, os trabalhos de Souza (2006) e de Vieira e Vidal (2014). O primeiro apresenta uma descrição do perfil sociodemográfico do diretor escolar com dados do Saeb de 2003, criando grupos de análise a partir dessas características. O segundo traça um perfil descritivo dos diretores escolares em nosso país, utilizando dados da Prova Brasil 2011. Nossa proposta é ampliar a reflexão proposta pelos autores, propondo uma análise evolutiva, com base nos dados disponíveis atualmente. Sobretudo, pretendemos levantar informações que alimentem a discussão no campo acadêmico e fomentem iniciativas públicas sobre a relevância do trabalho do(a) diretor(a) na construção de uma educação de qualidade.

\section{Diretores das escolas públicas brasileiras: perfil dos últimos anos (2007- 2015)}

Quem são os diretores e diretoras das escolas públicas brasileiras? Os dados das edições da Prova Brasil (2007 a 2015) nos permitem conhecer seu Revista Educação Online, Rio de Janeiro, n. 27, jan-abr 2018, p. 49-72 
perfil de forma bastante abrangente, considerando o volume de informações coletadas nos questionários.

No que se refere às características sociodemográficas dos diretores e diretoras das escolas públicas brasileiras, testadas nas edições da Prova Brasil, a grande maioria é constituída por pessoas do sexo feminino (cerca de $80 \%$ ao longo do período pesquisado, enquanto o índice para o sexo masculino se manteve em torno de 20\%). Cabe ressaltar que, embora a porcentagem de diretores do sexo masculino seja bem menor, houve pequena elevação dessa taxa (próxima a 2\%) desde 2007.

No que se refere às características de cor, temos uma queda gradativa na porcentagem dos que se declararam brancos (52,1\% em 2007 para 46,7\% em 2015), enquanto a porcentagem dos que se declararam pardos oscilou entre $35 \%$ e $45 \%$ no período analisado. Essas são as duas categorias que concentram o maior número de diretores e diretoras ao longo do período analisado. Porém, nesse quesito, chama à atenção a porcentagem de diretores e diretores que se autodeclararam pretos: evolui gradativamente de $6,8 \%$, em 2009 , para $8,4 \%$, em 2015. Esse fato, em alguma medida, deve estar relacionado às políticas de ações afirmativas que contribuíram, entre outras coisas, para o maior acesso dessa parcela da população aos cursos superiores e para a percepção da identidade negra.

A faixa etária desses diretores e diretoras apresenta algumas modificações ao longo dos últimos anos, como mostra o gráfico abaixo:

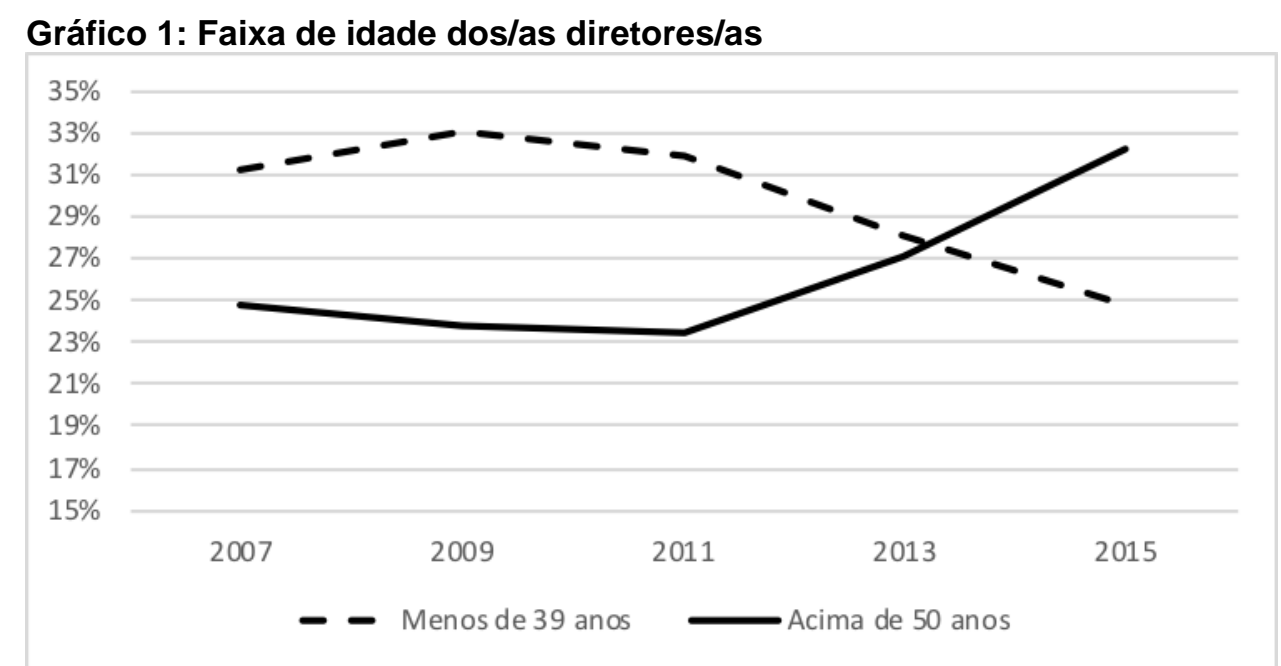

Fonte: Produzido pelas autoras, com dados do Inep 
De acordo com os dados, a idade média dos diretores e diretoras das escolas públicas brasileiras está mais elevada nos últimos anos:

a porcentagem de diretores acima de 50 anos passou de 24,7\% (2007) para $32,2 \%$ (2015), enquanto a de diretores com menos de 39 anos diminuiu de $31,2 \%$ (2007) para 24,7\% (2015). É importante ressaltar que o aumento na faixa etária não significa, necessariamente, maior experiência na função. Sobre esse aspecto, o gráfico a seguir sintetiza as informações:

Gráfico 2: Experiência em Educação, como Diretor e como Diretor na atual escola.

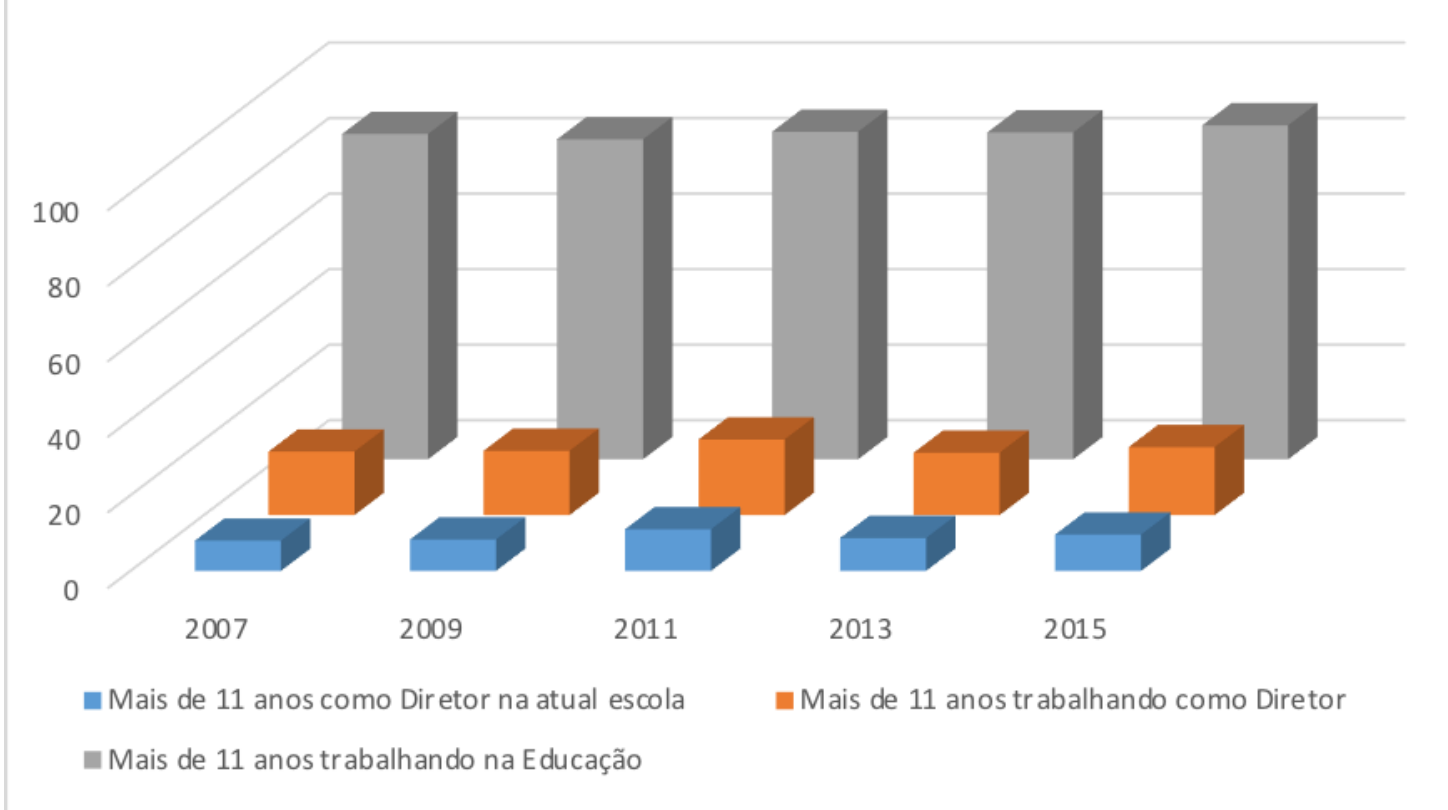

Fonte: Produzido pelas autoras, com dados do Inep

Como se pode observar, quanto à experiência trabalhando em educação, há um alto percentual, em todos os períodos, de diretores e diretoras com mais de 11 anos de experiência (próximo a 85\%), apresentando pequena oscilação. Esse dado corrobora a ideia de que essa é uma categoria que, em sua grande maioria, possui bastante experiência em educação, provavelmente, experimentando a sala de aula antes de assumir o cargo.

Apesar da alta proporção de diretores com longo tempo de experiência na área educacional, os dados sobre a experiência nessa função apresentam tendência mais baixa. Ao longo do período observado, a proporção de diretores e diretoras com mais de 11 anos na função variou entre 16,5\% e 20\%. Destaca-se, na análise dos dados, que $73,6 \%$ dos respondentes afirmaram estar exercendo a função há menos de cinco anos em 2015, fato que indica a pouca experiência na 
função ou uma grande rotatividade no cargo, apesar da grande experiência em educação demonstrada anteriormente.

Da mesma forma, a experiência como diretor ou diretora na atual escola, apresentou pouca variação ao longo do período (8,0\% dos respondentes, em 2007, e 9,6\%, em 2015, estavam havia mais de 11 anos exercendo o cargo na atual escola). Em 2015, 73,2\% dos respondentes afirmam estar à frente da atual escola há menos de cinco anos (esse percentual era de 68,3\% em 2007). Ou seja, os dados relativos à menor experiência como diretor ou diretora e o menor tempo de experiência na função em uma mesma escola podem indicar uma relação que precisaria ser analisada com maior profundidade. Segundo os dados, o período de permanência na função, em geral, é pequeno, o que instiga algumas hipóteses: assumiriam a posição de diretor(a) professores(as) próximos ao tempo de aposentadoria? Qual a relação entre o tempo de experiência na função e o acesso por indicação, tendo em vista que essa se apresenta como uma das formas que menos proporciona a permanência na função? Veremos algumas considerações sobre esse último aspecto mais adiante.

No que se refere à sua formação inicial, estariam os diretores(as) preparados para assumir os desafios da função?

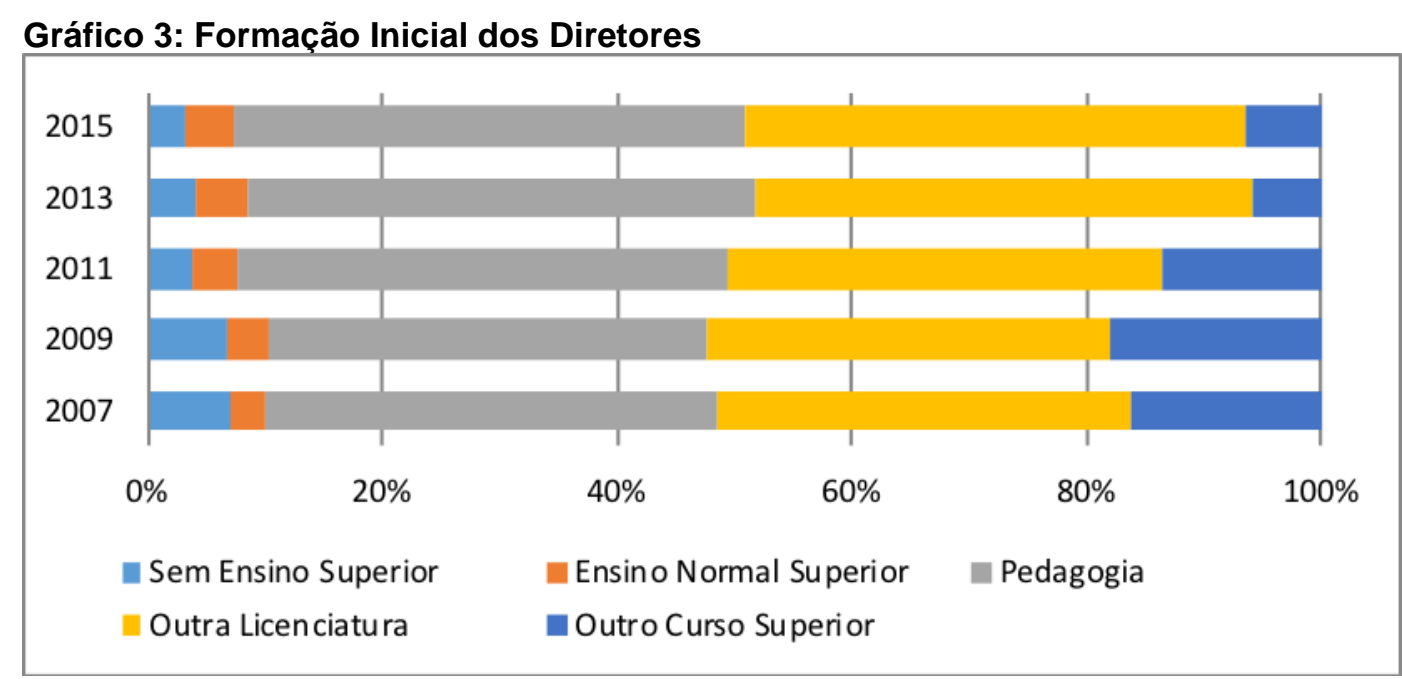

Fonte: Produzido pelas autoras, com dados do Inep

Os dados do período analisado mostram que a grande maioria possui ensino superior nas áreas de pedagogia ou licenciaturas (entre 70\% e 80\%), e que essa taxa cresceu gradativamente de 2009 a 2015. Em contrapartida, há uma queda progressiva a proporção de diretores e diretoras sem curso superior (de $7 \%$, em 2007, para 3,1\%, em 2015) e na proporção de diretores e diretoras 
que concluíram outro curso superior (de 16,1\%, em 2007, para 6,2\%, em 2015), o que pode estar vinculado à implementação de medidas que incentivam ou exijam, de alguma maneira, um nível mínimo de formação para a função. Considerando que não conseguimos ainda superar completamente essa deficiência, esse importante dado merece acompanhamento e será explorado mais à frente.

Quanto à formação continuada, a maioria possui especialização, sendo que essa proporção apresenta crescimento ao longo dos períodos, passando de $57,8 \%$, em 2007 , para $74,6 \%$, em 2015 , enquanto a taxa de diretores e diretoras que declararam "não fiz ou não completei o curso", apresentou uma queda acentuada, passando de $32,7 \%$ para $17,1 \%$ no mesmo período. Esses dados são sugestivos de que existe uma tendência à formação continuada, mas somente na modalidade "especialização", uma vez que a proporção de respondentes com mestrado apresenta crescimento muito pequeno (de 1,6\% para $3 \%$ ) e a proporção de diretores e diretoras doutores praticamente se manteve em torno de $0,3 \%$. Acreditamos que uma das possibilidades para tal fato, é a de que a pósgraduação latu sensu é oferecida, muitas vezes, aos sábados ou a distância. Tempo é um fator decisivo para os que possuem suas cargas horárias comprometidas com a função, portanto, decisivo também na escolha do tipo de formação.

Vislumbramos uma mudança crescente na proporção de diretores e diretoras com formação continuada, o que vai ao encontro do que propõe o atual Plano Nacional de Educação (2014-2024) ${ }^{5}$.

Sobre a forma de acesso à função de diretor, agrupamos os dados em três grupos: Seleção e/ou Eleição, Indicação e Outra forma. As respostas agrupadas na primeira faixa incluem: Eleição apenas; Processo Seletivo apenas; Processo Seletivo e eleição (a partir da Edição de 2013, o questionário inclui a opção Concurso Público apenas, também inserida nessa faixa). As respostas agrupadas na segunda faixa incluem: Indicação de técnicos; Indicação de políticos, Outras Indicações (A partir de 2013, essas opções foram condensadas em: Indicação

\footnotetext{
5 Em sua meta 16, o documento tem como um dos objetivos, garantir a todos(as) os(as) profissionais da educação básica formação continuada em sua área de atuação, considerando as necessidades, demandas e contextualizações dos sistemas de ensino.
} 
apenas $\left.^{6}\right)$. Procuramos destacar, com essa organização, critérios baseados em aspectos de comprovação técnica e de consulta à comunidade (na primeira faixa), em contraste com processos de indicação, que tendem a privilegiar relações políticas e/ou pessoais na escolha do diretor escolar (segunda faixa). 0 gráfico abaixo sintetiza as informações para o período:

Gráfico 4: Acesso ao cargo de Diretor (\%)

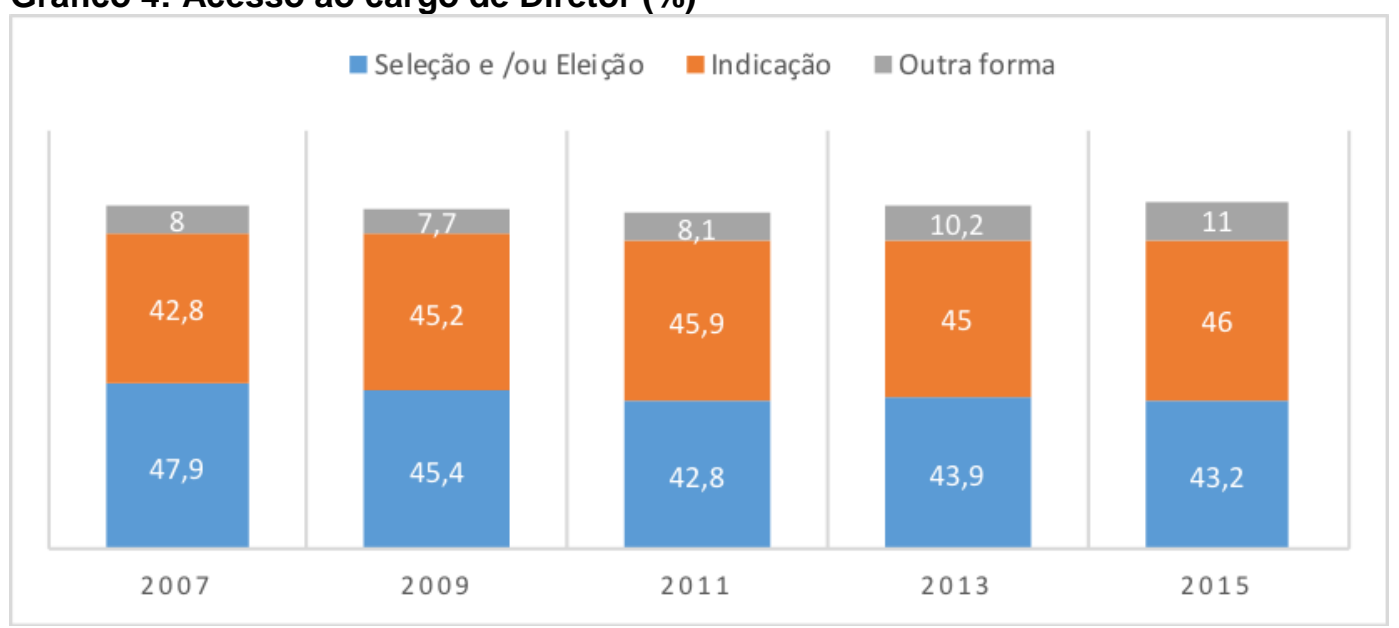

Fonte: Produzido pelas autoras, com dados do Inep

Observando a distribuição das proporções, temos que a primeira faixa oscilou, diminuindo gradativamente de 2007 a 2011, voltando a diminuir de 2013 a 2015. Por outro lado, a proporção de respondentes que acessaram a posição de diretor(a) por indicação apresentou crescimento, ainda que discreto, em praticamente todos os períodos, o que parece demonstrar a manutenção de uma tradição nesse tipo de acesso. Como apontam Oliveira e Carvalho (2015),

A indicação de diretores para as escolas públicas brasileiras (historicamente uma escolha política local, que pode não considerar nenhuma capacidade educacional ou de gestão) é parte da tradição patrimonial na administração pública brasileira. Estas práticas parecem encontrar ainda um terreno fértil, especialmente no nível municipal, criando espaço, muitas vezes, para um clientelismo político e partidário. (p.10)

Cabe ressaltar que a permanência no cargo mediante a indicação, sobretudo política, tende a ser restrita, devido a sua própria dinâmica, que pode mudar a cada eleição ou a cada novo acordo político. É muito importante observarmos esse fato, uma vez que a permanência no cargo tem demonstrado ser um fator importante para um melhor desempenho dos estudantes. Segundo o

\footnotetext{
${ }^{6}$ A partir de 2013, foi incluída a opção Processo Seletivo e Indicação (com porcentagem de 5,1\% dos respondentes, em 2013, e 6,0\%, em 2015), que, por reunir características das duas faixas criadas, foi considerada na categoria Outra forma.
}

Revista Educação Online, Rio de Janeiro, n. 27, jan-abr 2018, p. 49-72 
PNE atual, a eleição é uma forma democrática de acesso ao cargo, sendo um dos objetivos da Meta 19:

assegurar condições, no prazo de 2 (dois) anos, para a efetivação da gestão democrática da educação, associada a critérios técnicos de mérito e desempenho e à consulta pública à comunidade escolar, no âmbito das escolas públicas, prevendo recursos e apoio técnico da União para tanto. A gestão democrática da educação não se constitui em um fim em si mesmo, mas em importante princípio que contribui para o aprendizado e o efetivo exercício da participação coletiva nas questões atinentes à organização e à gestão da educação nacional, incluindo as formas de escolha de dirigentes e o exercício da gestão. (BRASIL, 2014)

Os dados apresentados nos mostram a necessidade de mudanças profundas nas políticas de provimento de cargo do diretor escolar para que as metas do PNE 2014-2024 sejam alcançadas. Considerando o prazo previsto de dois anos para assegurar a gestão democrática com ampla consulta à comunidade escolar, que expirou em 2016, podemos ter expectativas de mudanças nesse aspecto no futuro próximo. Portanto, precisamos acompanhar os dados referentes à Prova Brasil 2017, para verificarmos se houve mudanças significativas nesses indicadores. Por ora, considerando a importância do tema, 0 retomaremos mais adiante, considerando as especificidades regionais de nosso país no que se refere a esse aspecto.

Procuramos apresentar, nesta seção, algumas informações relevantes, que nos ajudam a conhecer o perfil dos diretores escolares que estiveram à frente das escolas públicas brasileiras nos últimos anos. Nas duas próximas seções, aprofundaremos a análise das informações referentes a aspectos relevantes na definição do perfil desse servidor: a sua formação inicial e o processo através do qual ele assumiu sua função. Como discutido anteriormente, o processo de federalização política em nosso país implica na descentralização de definições sobre a escolha de diretores para as escolas públicas. Assim, fica a cargo de cada sistema educacional a definição dos critérios para essa escolha, inclusive no que se refere à exigência de formação mínima para o exercício da função. Como veremos a seguir, estes dois aspectos - a formação inicial do(a) diretor(a) e a forma através da qual ele(a) assumiu sua função - podem estar proximamente relacionados. 


\section{A formação inicial e continuada dos diretores das escolas públicas brasileiras}

A legislação educacional brasileira tradicionalmente estabeleceu a formação inicial de administradores escolares no âmbito da formação dos profissionais da educação. Desde a LDB de 1971, instituiu-se que essa formação específica deveria se dar em curso superior de graduação ou de pós-graduação. A LDB de 1996 (Lei № 9.394/96) praticamente manteve as orientações vigentes desde 1971, acrescentando a especificação do curso de graduação:

a formação de profissionais de educação para administração, planejamento, inspeção, supervisão e orientação educacional para a educação básica será feita em cursos de graduação em pedagogia ou em nível de pós-graduação, a critério da instituição de ensino, garantida, nesta formação, a base comum nacional. (Art. 64)

Contudo, uma vez que se considerem os diretores escolares como um dos profissionais de educação incluídos na legislação citada, essa indicação não vem sendo totalmente contemplada, como apontaram os dados apresentados na seção anterior. Como foi mostrado, ainda que tenha havido uma involução significativa na porcentagem de diretores que não possuíam formação inicial em licenciaturas, essa taxa é bastante desigual entre as unidades federativas. Os gráficos a seguir destacam alguns contrastes:

\section{Gráfico 5: Diretores sem curso superior - Contrastes entre Unidades da Federação}

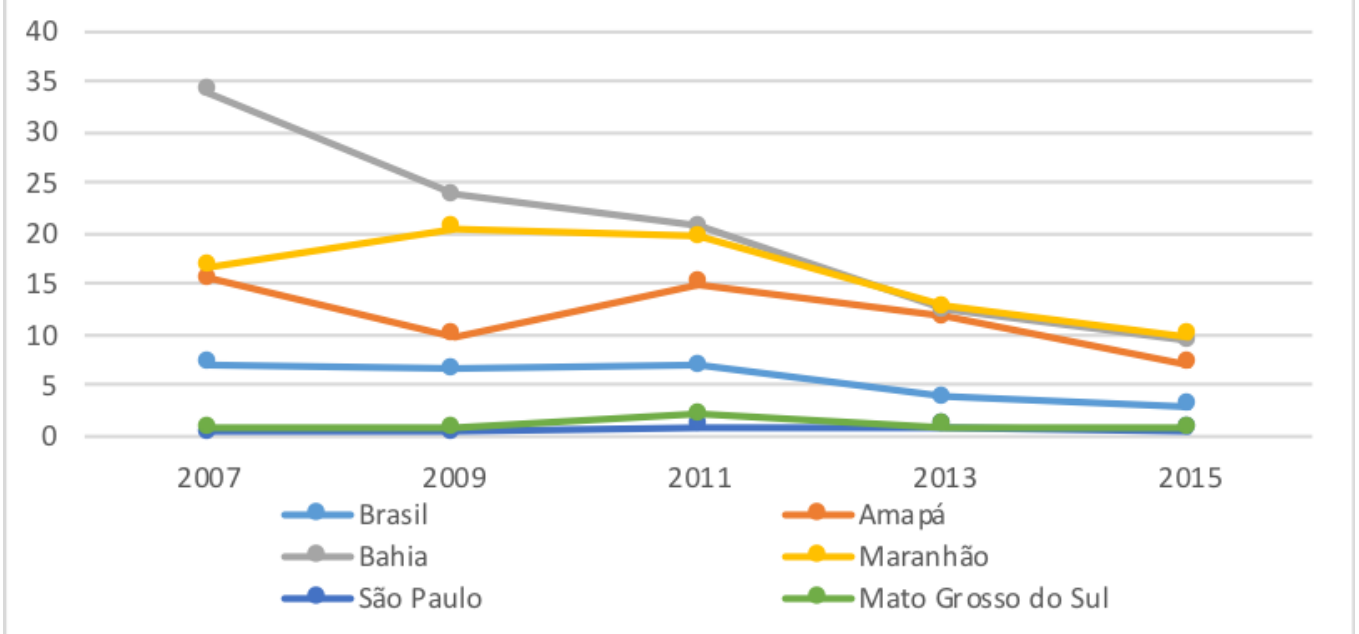

Fonte: Produzido pelas autoras com dados do Inep

Destaca-se, na leitura do gráfico acima, que a porcentagem de diretores sem formação em nível superior, nos estados da Bahia, Maranhão e Amapá, é significativamente superior à média brasileira no início do período observado. 
Ainda que essas taxas tenham se reduzido nos anos seguintes, ainda se encontram altas quando comparadas à média nacional (em 2015, 3,1\% dos diretores brasileiros declararam não ter formação em nível superior). No mesmo gráfico, encontramos os exemplos dos estados de São Paulo e Mato Grosso do Sul que, ao contrário, apresentaram ao longo do período analisado, um baixíssimo percentual de diretores sem formação em nível superior (em 2015: $0,6 \%$ e $0,8 \%$, respectivamente).

Gráfico 6: Diretores formados em outros cursos (não Licenciatura) - Contrastes entre Unidades da Federação

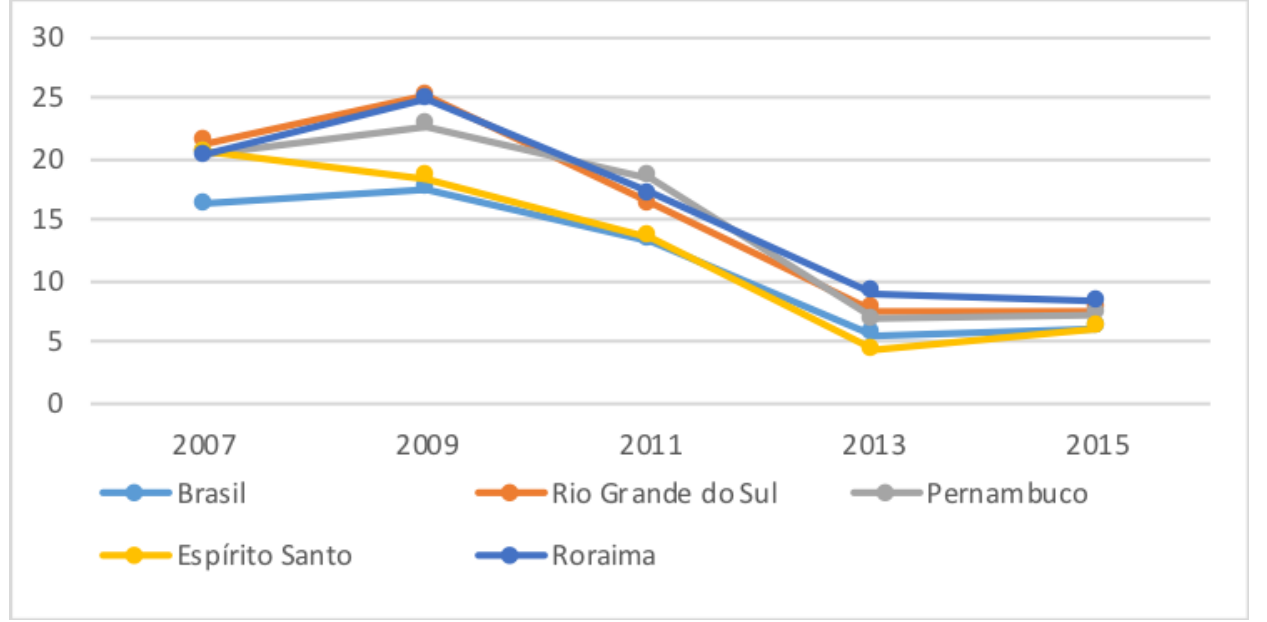

Fonte: Produzido pelas autoras com dados do Inep

Consideramos, também, o percentual de diretores(as) que declararam ter concluído o ensino superior, porém, em outras áreas diferentes da licenciatura. Como pode ser visto no gráfico acima, os estados do Rio Grande do Sul, Pernambuco, Espírito Santo e Roraima apresentam, no início do período analisado, taxas acima da média nacional. Porém, o percentual dos(as) diretores(as) com esse perfil cai ao longo do período, tanto nacionalmente como nesses estados e, de forma mais acentuada, no Espírito Santo (no Brasil, em 2015, 6,2\% dos diretores declararam ter concluído o ensino superior em outra área). Essa redução, como pôde ser visto no Gráfico 4, se reflete no aumento das taxas de diretores formados nas licenciaturas.

Nos últimos anos, a formação específica para a gestão escolar na educação básica tem se expandido, no Brasil, em cursos de formação continuada e/ou de pós-graduação. Sobre esse tema, Aguiar (2011) destaca o impulso para a formação continuada de gestores escolares em nosso país, a partir dos anos 2000, dando especial destaque para o Programa Nacional Escola de Gestores da Educação Básica - Pnegeb, lançado em 2004. O Pnegeb surgiu da necessidade 
de "construir processos de gestão escolar compatíveis com a proposta e a concepção da qualidade social da educação, baseada nos princípios da moderna administração pública e de modelos avançados de gerenciamento de instituições públicas de ensino" (BRASIL, 2009). Nesse sentido, apesar do impulso demonstrado a partir de tal iniciativa, essa formação não atingiu a totalidade dos diretores das escolas públicas brasileiras (como será apresentado a seguir). Consideramos que seus resultados sejam cada vez mais significativos em abordagens futuras. Porém, como já aventado, precisamos estar atentos às políticas locais para a escolha de diretores em algumas secretarias de educação, em que se tem observado a suspensão da obrigatoriedade desse tipo de especialização para o exercício da função. Esse é o caso da SME do Rio de Janeiro, que mudou recentemente o processo de escolha de diretores escolares em sua rede, alterando a ordem nos processos de comprovação técnica, de mérito e consulta à comunidade, previstos no PNE 2014-2024.

Em 2015, 82,8\% dos diretores escolares declararam ter cursado alguma modalidade de pós-graduação, ainda que não esteja especificado no questionário que esse curso tenha sido na área da gestão escolar (em 2007, essa porcentagem era de 66,4\%). Com efeito, a agenda da política pública educacional parece ter priorizado, nos últimos anos, o investimento na formação continuada de gestores escolares. Porém, assim como no caso da formação inicial, esse referencial varia entre os estados brasileiros, como pode ser visto no gráfico abaixo:

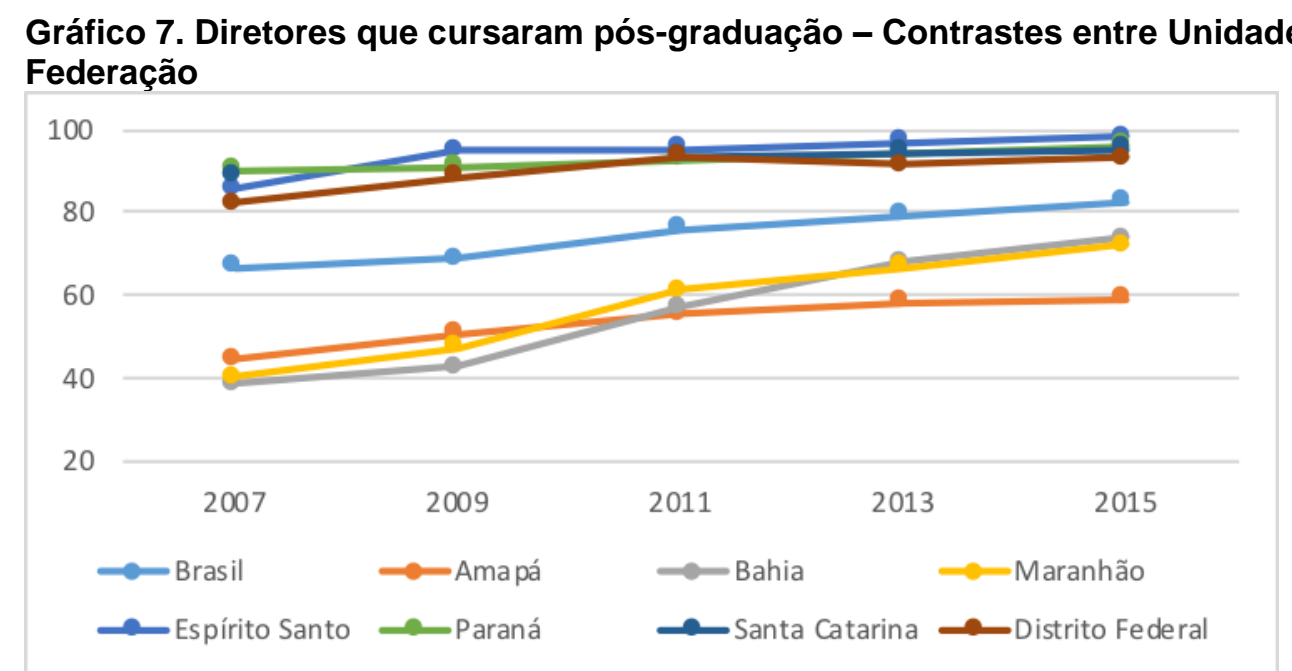

Fonte: Produzido pelas autoras com dados do Inep 
No gráfico, destacamos os estados que apresentaram as maiores e as menores porcentagens de diretores(as) que declararam ter cursado pósgraduação (esses estados se mantiveram nessa posição ao longo do período analisado). Percebe-se a tendência nacional de investimento na formação desses profissionais, nessa modalidade, inclusive daqueles que, em 2007, apresentavam taxas bem inferiores à média nacional. No caso dos estados destacados, ressalta-se que esse encaminhamento teve maior força política na Bahia e no Maranhão, enquanto o Amapá mantém uma trajetória mais lenta.

Consideramos de fundamental importância questionar o que estamos entendendo, no Brasil, como formação acadêmica esperada para o exercício dessa função. Nesse ponto, é importante ressaltar que, no campo dos estudos sobre a gestão educacional, não se chegou a um consenso sobre a eficiência da formação inicial e continuada do diretor ${ }^{7}$. Souza (2008) faz uma importante análise sobre a questão, argumentando que a falta de uma consistência teórica no campo das pesquisas em gestão escolar resulta em uma formação ineficiente. Essa importante discussão, contudo, foge do escopo deste trabalho. Por ora, buscaremos compreender os determinantes dos contrastes encontrados em nossa análise evolutiva sobre o tema. Como sugerimos anteriormente, o perfil do(a) diretor(a) das escolas públicas brasileiras fica condicionado aos diferentes critérios de escolha para o exercício da função, determinados pelas políticas locais. A próxima seção apresenta os dados referentes a essa dinâmica.

\section{A escolha dos diretores: diferentes políticas no território nacional}

O Plano Nacional da Educação - PNE 2014-2024, como já apresentado, assume a discussão sobre a escolha dos diretores escolares nas escolas públicas, destacando-a como importante estratégia na condução da gestão democrática nas escolas. Em sua Meta 19, o plano reforça a efetivação da gestão democrática, propondo, como uma das estratégias, que se "considere, conjuntamente, para a nomeação dos diretores e diretoras de escola, critérios técnicos de mérito e desempenho, bem como a participação da comunidade escolar" (BRASIL, 2014). Contudo, como vimos na apresentação dos dados nacionais, essa realidade ainda está distante de se concretizar. Mendonça (2000)

${ }^{7}$ A esse respeito, ver Souza, 2008; Souza, 2005; Paro, 2009.

Revista Educação Online, Rio de Janeiro, n. 27, jan-abr 2018, p. 49-72 
assinala que a escolha de diretores escolares nas redes públicas do país tem se apresentado, frequentemente, por meio de quatro modalidades: indicação, política ou técnica pelos governos municipais e estaduais; concurso público, que avalia a competência técnica através de provas e títulos; eleição, através de voto direto da comunidade escolar; e modalidades mistas, que integram a eleição a processos que comprovem a competência técnica do candidato ao cargo. Ao observarmos como os(as) diretores(as) são escolhidos para sua função, nos diferentes estados brasileiros, podemos perceber que essas modalidades tendem a se delinear de forma bastante contrastante. Usando a classificação "Indicação" e "Seleção e/ou Eleição", como na apresentação dos dados nacionais, destacamos nos gráficos abaixo os principais contrastes encontrados na nossa análise:

\section{Gráfico 7. Escolha de Diretores: Indicação}

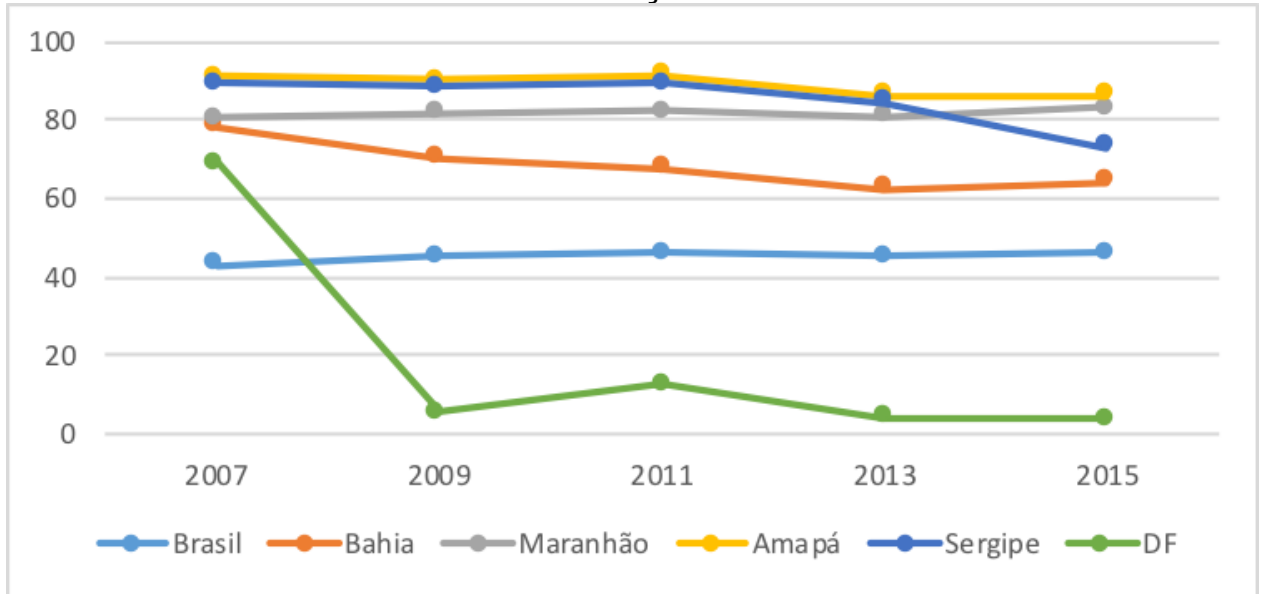

Fonte: Produzido pelas autoras com dados do Inep

Gráfico 8. Escolha de Diretores: Seleção e/ou Eleição

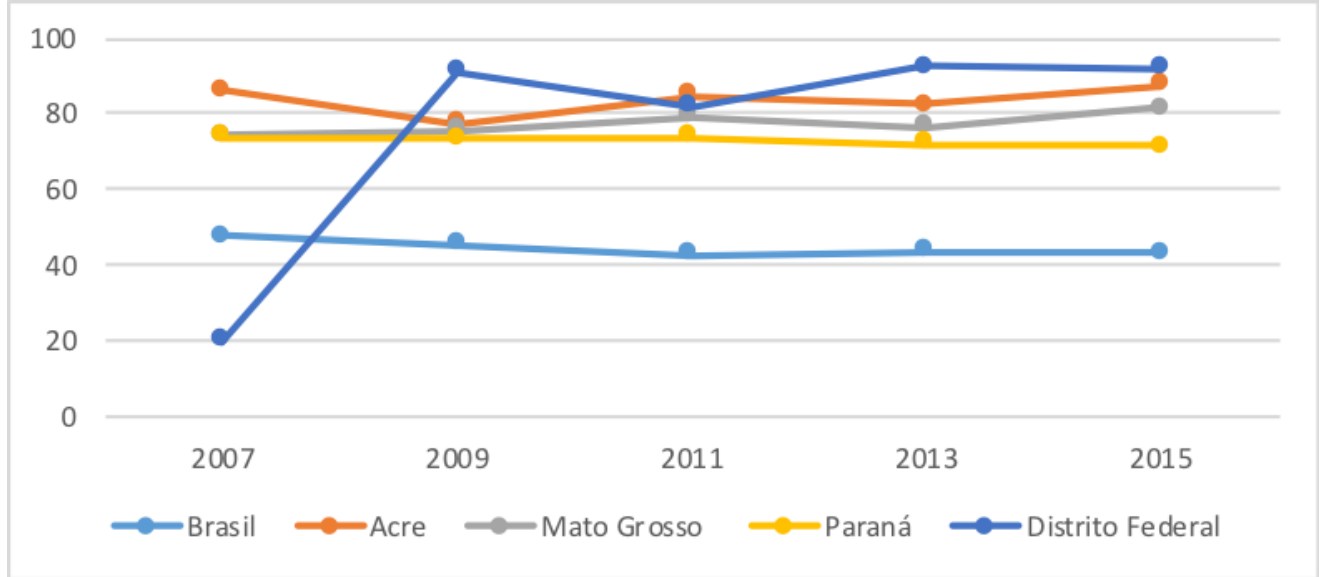

Fonte: Produzido pelas autoras com dados do Inep 
$\mathrm{Na}$ análise dos dados apresentados pelos gráficos acima, chama a atenção o caso do Distrito Federal, onde parece ter havido uma mudança radical na forma de escolha dos(as) diretores(as) em 2009. O estudo de Mendes (2012) traz um quadro evolutivo das políticas de escolha de diretores(as) escolares naquele contexto e nos ajuda a entender essa mudança. Em 2007, esses servidores eram escolhidos através de uma lista tríplice, com indicação do governador, conforme a Lei Distrital 247/99, que vigorou de 2000 a 2007. Entre 2008 e 2011, os diretores de Brasília deveriam participar de um processo seletivo e de eleições para acessarem a posição, mudança introduzida pela Lei Distrital 3046/07. Em 2012, a gestão de Agnelo Queiroz introduziu a eleição direta como única forma de escolha de diretores.

Já nos estados, as mudanças são mais lentas, pois os resultados de uma alteração nessas informações dependem das diferentes políticas municipais, principais responsáveis pelo ensino fundamental, etapa da educação a que se referem os dados desta pesquisa. Em alguns casos, apesar de haver uma tendência à adoção de processos mais democráticos para a escolha de diretores(as) na rede estadual, os sistemas municipais mantêm a tendência patrimonialista, mantendo a indicação (especialmente, a política) como estratégia de escolha de diretores. Entre eles, destacamos o caso da Bahia onde, apesar de haver, desde 2008, uma lei estadual que instituiu a eleição como uma das etapas de acesso à função (aliada à formação mínima e experiência na escola), essa mudança não se reflete nos dados analisados que concentram escolas da rede municipal. Assim, consideramos que a proporção de diretores indicados caiu significativamente na rede estadual baiana (sendo de 31\%, em 2015, abaixo da média nacional). Porém, as políticas municipais daquele estado tenderam a manter a indicação como principal forma de escolha de seus(suas) diretores(as).

Alguns estados apresentam, desde 2007, porcentagens de diretores que assumiram sua posição na escola através de eleição e/ou seleção, muito acima da média nacional. É o caso do Acre, que tem, desde 2003, uma legislação estadual que regulamenta a gestão democrática e estabelece, em seu artigo 10: "Os candidatos aprovados no processo seletivo serão submetidos à eleição direta e secreta pela comunidade escolar nas unidades de ensino" (Lei n. 1.513 de 11 
de novembro de 2003) ${ }^{8}$. As políticas municipais parecem seguir a mesma tendência atualmente, uma vez que, ao isolarmos os dados referentes somente à rede municipal de ensino, encontramos uma porcentagem parecida com a média do estado para todas as redes (88\%).

Tendo apresentado alguns contrastes no território nacional, no que se refere às informações sobre o nível de formação dos diretores e os diferentes processos de escolha desse servidor, passaremos a discutir as possíveis relações entre essas duas informações. Não por acaso, os estados com piores indicadores de formação de seus diretores (BA, MA e AP) estão entre aqueles com maiores taxas de diretores indicados. Com efeito, quando o acesso ao cargo depende mais de relações pessoais do que de critérios técnicos préestabelecidos (mérito e/ou desempenho) e da legitimação da comunidade (eleição), a definição do nível de formação esperada desses profissionais fica em segundo plano. Os dados do quadro abaixo apresentam essa relação em nível nacional:

Quadro 2:Forma de provimento da função X Formação (Prova Brasil, 2015)

\begin{tabular}{|l|c|c|c|}
\hline & Eleição e/ou Seleção & Indicação & Concurso Público \\
\hline Sem curso Superior & 1,4 & 5,2 & 0,9 \\
\hline Com pós-graduação & 88,1 & 77,6 & 87,8 \\
\hline
\end{tabular}

Fonte: Produzido pelas autoras, com dados do Inep

De acordo com o quadro, podemos observar que, entre os diretores indicados para a função, estão aqueles com a formação mais fraca. Ao levarmos em consideração o PNE, que preconiza os critérios de mérito, desempenho e consulta à comunidade na escolha dos diretores das escolas públicas brasileiras, muito ainda deverá ser feito para que a meta 19 seja cumprida.

\section{Considerações finais}

Neste artigo, procuramos evidenciar o perfil dos profissionais que assumem a função de diretor(a) escolar nas escolas públicas brasileiras (estaduais e municipais). Com base nos dados fornecidos pelo Inep, nas edições da Prova Brasil (2007 a 2015), analisamos a evolução de alguns dados sociodemográficos, dando especial destaque à variação na faixa etária desses profissionais ao longo do período. Como foi discutido, a tendência de

${ }^{8}$ Disponível em:< http://www.al.ac.leg.br/leis/?p=5558>. Acesso em: 10/01/2018.

Revista Educação Online, Rio de Janeiro, n. 27, jan-abr 2018, p. 49-72 
diretores(as) mais velhos(as), nos últimos anos, não coincide com a predominância de diretores com maior experiência na função. Ao contrário, parece estar havendo nos últimos anos, diretores que permanecem menor tempo na função, o que pode estar relacionado a mudanças nas políticas de alocação de diretores(as) e merece ser mais bem aprofundado.

Em nosso estudo, destacamos dois aspectos na observação do perfil do(a) diretor(a): sua formação e o acesso à sua posição. Como foi discutido, ambos dependem de políticas locais, que definem, em cada sistema, características esperadas desse servidor público. A descentralização na condução do tema produz contrastes entre as unidades federativas, conforme apresentado, que repercutem, certamente, na rotina escolar. Alguns estudos (OLIVEIRA; CARVALHO; LIMA, 2013; OLIVEIRA; CARVALHO, 2015) já demonstraram que a forma através da qual o(a) diretor(a) foi escolhido(a) apresenta associação significativa na explicação da variação na percepção do corpo docente sobre a liderança desse diretor e, também, no desempenho dos alunos nos testes de matemática. Utilizando também dados da Prova Brasil (2007, 2009 e 2011), porém, considerando os questionários respondidos por professores e alunos, Oliveira e Carvalho (2015) buscaram explicações para a variação nos resultados escolares a partir das características dos diretores. Em estudo estatístico controlando as características socioeconômicas dos alunos, encontraram uma associação estatisticamente significativa e negativa entre a variável "Diretor indicado para o cargo" e os resultados dos alunos nos testes de matemática (resultado médio por escola), nas três edições. A partir das respostas dos professores, as autoras criaram o Índice de Percepção da Liderança do Diretor, que teve uma associação significativa e positiva com os resultados dos alunos. $O$ resultado encontrado pelas autoras indica que:

controladas as características sociais (NSE médio das escolas), as variáveis usadas no modelo (Índice de Liderança do Diretor e Indicação para o cargo) explicariam cerca de $20 \%$ da variação dos resultados dos alunos do $5^{\circ}$ ano em matemática no período observado. (OLIVEIRA; CARVALHO, 2015, p.11)

O trabalho de Oliveira e Carvalho (2015) demonstrou estatisticamente os efeitos que a prática de indicação para a função de diretor (normalmente, política) podem ter nos resultados da escola. Essa relação poderia ser explicada pela formação menos qualificada desses diretores e pelas relações de pouca representatividade com o corpo docente. Destaca-se, assim, a relevância do 
tema a partir de um estudo que envolveu dados de todo o Brasil. Neste estudo, procuramos conhecer um pouco mais sobre as formas de escolha do diretor das escolas públicas brasileiras, considerando a evolução dos dados e as especificidades regionais.

Para a análise dos dados do Inep relativos à formação e acesso à função de diretores (as), nos pautamos nas indicações legais sobre o tema, especialmente a LDB e o atual PNE. Para compreender as especificidades regionais, foi necessário recorrer a dados relativos às legislações de algumas unidades da federação, buscando respostas para os contrastes encontrados. Certamente, um aprofundamento nos dados municipais e suas respectivas regulamentações sobre os dois aspectos levantados ampliaria essa discussão. Por fugir ao escopo deste trabalho, fica como desafio futuro.

A desigualdade social é uma realidade e um desafio no nosso país, e isso se reproduz na educação. Como sabemos, a condição socioeconômica ainda é o maior preditor da trajetória escolar e, em uma sociedade amplamente desigual como a nossa, essa afirmação tem nos desafiado a pensar estratégias que possibilitem uma distribuição mais equitativa da educação. Em se tratando do estudo apresentado, é importante observar uma característica regional nessa distribuição, nos gráficos relativos à formação inicial e em pós-graduação dos gestores das escolas públicas brasileiras.

Entre os gestores sem nível superior, as maiores taxas estão nos estados do norte e nordeste, enquanto os estados onde praticamente todos os diretores possuem ensino superior, já há alguns anos, estão localizados no sudeste. Apesar do relativo crescimento na taxa de formação continuada ao longo dos anos, alguns estados apresentam taxas inferiores a $60 \%$ de diretores pósgraduados, enquanto outros ultrapassam os $90 \%$. Não por acaso, estados do norte e nordeste apresentam taxas inferiores, enquanto os das regiões sul e sudeste apresentam taxas superiores. Consideramos esse dado como um dos mais significativos, uma vez que, além de reproduzir os distanciamentos regionais que historicamente acompanhamos no Brasil, abrem a possibilidade de reflexão sobre a manutenção dessa reprodução. Tendo em vista que a formação profissional, assim como a formação continuada, deve ser um dos principais pilares de uma instituição educacional, ela se justificaria pela possibilidade de 
melhorar a oferta educacional (ainda que haja controvérsias sobre o saber profissional esperado do diretor escolar).

Essa grande distância no nível de formação inicial e continuada desses profissionais, encontrada entre alguns estados brasileiros, demonstra o quanto de desigualdade temos ainda a enfrentar. Como buscamos problematizar, há uma relação entre o nível de formação (inicial e continuada) e a forma de escolha do profissional em cada rede de ensino. Como vimos, os estados que apresentam altas taxas de diretores indicados estão localizados nas regiões norte e nordeste, corroborando com o perfil político historicamente coronelista da região. Esse é outro grande desafio, implementar a gestão democrática, levando em consideração, na escolha dos diretores escolares, critérios técnicos de mérito e desempenho e a participação da comunidade escolar em todos os estados do país e em cada escola brasileira, segundo definido no PNE.

Nesse sentido, entendemos como gestão democrática mais do que a possibilidade de participação dos atores envolvidos na escolarização de crianças e adolescentes nas decisões da escola, incluindo a escolha do(a) diretor(a). Uma gestão democrática deve se pautar pela realização de um trabalho que oportunize uma distribuição mais equitativa e democrática dos saberes escolares. Assim, torna-se fundamental conhecer quem são os profissionais que assumirão esse compromisso e como auxiliá-los nessa tarefa, que é de todos nós.

\section{Referências bibliográficas}

AGUIAR, M. A. S. Formação em gestão escolar no Brasil nos anos 2000: políticas e práticas. Revista Brasileira de Política e Administração da Educação, v.27, n.1, p. 67-82, jan-abr 2011.

ALVES, M. T. G.; FRANCO, C. A pesquisa em eficácia escolar no Brasil: evidências sobre o efeito das escolas e fatores associados à eficácia escolar. In: BROOKE, Nigel; SOARES, José Francisco (Orgs.). Pesquisa em eficácia escolar: origem e trajetórias. Belo Horizonte: Editora UFMG, 2008. p. 482-500.

BRASIL. Lei de Diretrizes e Bases da Educação Nacional, Lei 9.394/96. Brasília, 1996. Disponível em: <http://www.planalto.gov.br>. Acesso em: 08 mar. 2012.

Lei no 13.005, de 25 de junho de 2014. Plano Nacional de Educação. Aprova o Plano Nacional de Educação - PNE e dá outras providências. Disponível em: <http://pne.mec.gov.br/>. Acesso em: 08 abr. 2015.

- Ministério da Educação. Instituto Nacional de Estudos e Pesquisas Educacionais Anísio Teixeira - INEP. Microdados da Aneb e da Anresc 2007, 
2009, 2011, 2013 e 2015. Brasília: Inep, 2017. Disponível em: <http://portal.inep.gov.br/basica>. Acesso em: 30 jan. 2017.

BRASIL. Ministério da Educação. Programa Nacional Escola de Gestores da Educação Básica Pública. Curso de Especialização em Gestão Escolar (Projeto de Curso). Disponível em: <http://portal.mec.gov.br>. Acesso em: 08 abr. 2015.

LEITHWOOD, K. ¿Cómo liderar nuestras escuelas? Aportes desde la investigación. Santiago: Salesianos Impresores, 2009.

; SUN, J. Transformational school leadership effects on schools, teachers and students. In: HOY, W. K.; DIPAOLA, M. (Eds.). School improvement. New York: Information Age, 2009. p. 1-22

SOUZA, A. M. Determinantes da aprendizagem em escolas municipais. Ensaio: Avaliação e Política Pública Educacional, v.13, n.49, p. 413-434, out-dez 2005.

MENDES, C. S. Como os modelos de escolha de diretores incidem na gestão escolar? 2012. Dissertação (Mestrado em Educação) - Faculdade de Educação, Programa de Pós-Graduação em Educação Universidade de Brasília, Brasília, 2012.

MENDONÇA, E. F. Estado patrimonial e gestão democrática do ensino público no Brasil. Educação \& Sociedade, v. 13, n. 75, p. 87, 2001.

OLIVEIRA, A.C.P. As relações entre direção, liderança e clima escolar em escolas municipais do Rio de Janeiro. 2015. Tese (Doutorado em Educação) Coordenação de Pós-Graduação, Pontifícia Universidade Católica do Rio de Janeiro, Rio de Janeiro, 2015.

; CARVALHO, C. Paes de; LIMA, F. School's democratic management and community participation: a study on two educational systems in Rio de Janeiro. In: UCEA Convention, Indianápolis, 2013.

Gestão escolar, liderança do diretor e resultados educacionais no Brasil. In: REUNIÃO ANUAL DA ANPED, 37., Trabalho apresentado no GT Sociologia da Educação. Florianópolis, 2015. Anais eletrônicos... Disponível em: <http://37reuniao.anped.org.br/trabalhos/>.Acesso em: 15 ago. 2016.

; WALDHELM, A.P.S. Liderança do diretor, clima escolar e desempenho dos alunos: qual a relação? Ensaio: Avaliação e Política Pública Educacional, v.24, n. 93, p. 824-844, out-dez 2016

PARO, V. H. Formação de gestores escolares: a atualidade de José Querino Ribeiro. Educação e Sociedade, v. 30, n. 107, p. 453-467, ago 2009. Disponível em <http://www.scielo.br>. Acesso em: 15 nov. 2017.

. Diretor escolar: educador ou gerente? São Paulo: Cortez, 2015.

PEREIRA, Luiz. A escola numa área metropolitana. São Paulo: Biblioteca Pioneira de Ciências Sociais, 1967.

SAMMONS, P. As características-chave das escolas eficazes. In: BROOKE, Nigel; SOARES, José Francisco (Orgs.). Pesquisa em eficácia escolar: origem e trajetórias. Belo Horizonte: Editora UFMG, 2008.

SOARES, J. F. Melhoria do desempenho cognitivo dos alunos do Ensino Fundamental. Cadernos de Pesquisa, v. 37, n. 130, p. 135-60, jan-abr. 2007. 
SOUZA, A. M. Determinantes da aprendizagem em escolas municipais. Ensaio: Avaliação e Política Pública Educacional, v.13, n.49, p. 413-434, out-dez 2005.

SOUZA, A. R. Perfil da gestão escolar no Brasil. 2006. Tese (Doutorado em Educação) - PUC-SP, São Paulo, 2006.

A produção do conhecimento e 0 ensino da gestão educacional no Brasil. Revista Brasileira de Política e Administração da Educação, v.24, n.1, p. 51-60, jan-abr 2008.

. A natureza política da gestão escolar e as disputas pelo poder na escola. Revista Brasileira de Educação, vol.17, n.49, p. 159-174, jan-abr 2012.

VIEIRA, S. L.; VIDAL, A. M. Perfil e formação de gestores escolares no Brasil. Dialogia, n. 19, p. 47-66, jan-jun 2014.

WEBER, M. ¿Qué es la burocracia? Buenos Aires: Editorial la Pléyade, 1977. 